\title{
Persepsi Masyarakat Betawi Terhadap Fenomena Ondel-Ondel Ngamen
}

\author{
Iren Chienita, Eko Harry Susanto, Septia Winduwati \\ Iren.915150035@stu.untar.ac.id,ekoh@fikom.untar.ac.id, septiaw@fikom.untar.ac.id. \\ Fakultas Ilmu Komunikasi Universitas Tarumanagara
}

\begin{abstract}
Ondel-ondel besides being an icon of Betawi culture, it has long been used and believed to be a repellent in traditional Betawi rituals. However, there is now an ondel-ondel ngamen phenomenon in the community. The purpose of this study is to find out how the perceptions of the Betawi people are related to the Ondel-ondel ngamen phenomenon which is seen from three aspects, namely cognitive, affective and conative. The concept used in this study is perceptions in communication theory and cultural theory. This research is a descriptive qualitative research with phenomenology method. Data collection techniques in this study used nonparticipant observation, in-depth interviews, literature studies and also online data tracking. The results of this study are cognitive perceptions of the Betawi people knowing that the completeness of Ondel-ondel singing is different from Ondel-ondel in Betawi folk shows, the affective perception of the Betawi community tends not to support the use of Ondel-ondel as a busking tool because of annoyance and concern, and the last the Betawi society's conative perception tend not giving money to Ondel ondel who was busking.
\end{abstract}

Keywords: Culture, Ondel-ondel, Perception.

\begin{abstract}
Abstrak
Ondel-ondel selain sebagai ikon budaya Betawi, sejak dahulu digunakan dan dipercaya sebagai penolak bala dalam ritual adat Betawi. Namun, kini muncul fenomena Ondel-ondel ngamen di tengah masyarakat. Tujuan dari penelitian ini ingin mengetahui bagaimana persepsi masyarakat Betawi terkait fenomena Ondel-ondel ngamen yang dilihat dari tiga aspek yaitu kognitif, afektif, dan konatif. Konsep yang digunakan dalam penelitian ini adalah persepsi dalam teori komunikasi dan teori budaya. Penelitian ini merupakan penelitian kualitatif deskriptif dengan metode fenomenologi. Teknik pengumpulan data dalam penelitian ini menggunakan observasi nonpartisipan, wawancara mendalam, studi pustaka dan juga penelusuran data online. Hasil dari penelitian ini adalah persepsi kognitif masyarakat Betawi terhadap kelengkapan Ondel-ondel ngamen yang berbeda dengan Ondelondel dalam acara rakyat Betawi, persepsi afektif masyarakat Betawi cenderung tidak mendukung penggunaan Ondel-ondel sebagai alat mengamen karena kesal dan prihatin, dan persepsi konatif masyarakat Betawi cenderung tidak memberikan uang kepada Ondel-ondel ngamen.
\end{abstract}

Kata Kunci: Budaya, Ondel-ondel, Persepsi.

\section{Pendahuluan}

DKI Jakarta merupakan ibu kota Indonesia yang selalu menjadi pusat tujuan bagi para pendatang baru. Berdasarkan data Dinas Kependudukan dan Catatan Sipil DKI Jakarta yang dilansir oleh Sindonews.com, jumlah pendatang baru ke Jakarta setelah Lebaran tahun 2017 sebanyak 70.752 orang. Hal ini menjadikan Jakarta 
sebagai ibu kota yang memiliki berbagai macam kebudayaan. Di samping itu, kebudayaan yang tak dapat terlepas dari ikon Jakarta adalah ondel-ondel yang berasal dari Betawi.

Ondel-ondel merupakan boneka raksasa yang memiliki tinggi sekitar 2,5 meter dan lebar sekitar 80 centimeter yang dibuat menggunakan anyaman bambu untuk bagian tubuhnya, topeng pada bagian wajahnya dan ijuk pada bagian rambutnya. Biasanya ondel-ondel tampil dengan memimpin barisan dalam acara perkawinan ataupun sunatan. Ondel-ondel pria memakai topeng merah dan berkumis, sedangkan perempuan bertopeng putih dengan bibir berlipstik merah (http://jakartatourism.go.id/2015/node/501?language=id, diakses pada 29 Agustus 2018 pukul 11.10pm). Dahulu Ondel-ondel dikenal dengan sebutan "barongan" dan dalam pembuatannya juga diperlukan beberapa ritual seperti sesajen yang berisi bubur merah-putih, rujak-rujakan tujuh rupa, bunga tujuh macam, dan juga asap kemenyan. Ketika Ondel-ondel sudah selesai dibuat, Ondel-ondel diberikan sesajen dan dibasuh dengan asap kemenyan yang disertai mantera-mantera (https://www.cnnindonesia.com/hiburan/20160622182515-241-140178/mengenalmakna-simbolik-ondel-ondel, diakses pada 30 Agustus 2018 pukul 2:26pm).

Terlepas tingginya para pendatang baru ke Jakarta selain kaya akan budaya, di sisi lain membuat Jakarta penuh dengan tenaga kerja. Akan tetapi, banyaknya tenaga kerja juga menyebabkan melonjaknya tingkat pengangguran. Hal ini didukung dengan data dari Katadata.co.id yang menyatakan bahwa jumlah pengangguran di DKI Jakarta pada Agustus 2017 mencapai 346.940 jiwa (https://databoks.katadata.co.id/datapublish/2017/11/17/angka-pengangguran-jakartadi-atas-tpt-nasional, diakses pada tanggal 30 Augusus 2018 pukul 5.37pm). Melihat tingginya jumlah pendatang baru dan jumlah pengangguran yang berada di Jakarta menjadikan banyak masyarakat berusaha untuk memenuhi kebutuhan sehari-hari dengan berbagai cara. Diantaranya dengan menfaatkan kebudayaan Betawi yaitu ondel-ondel. Ondel-ondel yang dahulu bernilai sakral kini harus beralih fungsi menjadi aktivitas yang bernilai ekonomis murni dikalangan masyarakat. Seperti ajang mata pencaharian oleh beberapa kelompok di ruang public (https://www.liputan6.com/news/read/3361235/fenomena-ondel-ondel-jadipengamen-jalanan-pemerintah-diminta-beri-pembinaan, diakses pada tanggal 27 Agustus 2018 pukul 09.15pm).

Paramita dalam artikel berjudul "Pergeseran Makna Budaya Ondel-ondel Pada Masyarakat Betawi Modern" melakukan penelitian tersebut untuk mengetahui bagaimana pergeseran makna Ondel-ondel yang terjadi pada masyarakat Betawi. Hasil penelitian tersebut menyatakan bahwa saat ini Ondel-ondel tidak hanya dijadikan sebagai hiasan maupun ritual persembahan, namun juga digunakan sebagai mata pencaharian oleh masyarakat Betawi. Hal ini dikarenakan adanya permasalahan dalam bidang sosial dan ekonomi yang menimpa masyarakat Betawi. Dengan demikian, maka permasalahan yang akan dibahas adalah bagaimana persepsi masyarakat Betawi mengenai fenomena Ondel-ondel ngamen?

\section{Metode Penelitian}

Dalam penelitian ini, penulis menggunakan pendekatan penelitian kualitatif. Menurut Jane Richie (dalam Moleong, 2008) penelitian kualitatif adalah upaya untuk menyajikan dunia sosial, dan perspektifnya di dalam dunia, dari segi konsep, perilaku, persepsi, dan persoalan tentang manusia yang diteliti. 
Penelitian ini bersifat deskriptif, menurut Singarimbun dan Effendi (dalam Bajari, 2015) penelitian deskriptif merupakan pengukuran yang cermat terhadap fenomena sosial tertentu. Tujuan penelitian deskriptif adalah mengembangkan konsep dan menghimpun fakta-fakta, bukan menguji hipotesis.

Fenomenologi menurut Husserl dapat diartikan sebagai pengalaman subjektif atau pengalaman fenomenologikal, suatu studi tentang kesadaran dari perspektif pokok dari seseorang (dalam Moleong, 2008).

Metode pengumpulan data yang digunakan oleh peneliti dalam penelitian ini adalah dengan menggunakan observasi nonpartisipan, wawancara mendalam, studi kepustakaan dan penelusuran online.

Observasi nonpartisipan, menjadikan peneliti sebagai penonton atau penyaksi terhadap gejala atau kejadian yang menjadi topik penelitian. Dalam observasi jenis ini peneliti melihat atau mendengarkan pada situasi sosial tertentu tanpa partisipasi aktif didalamnya. Observasi non partisipan memiliki kelebihan dari sudut objektivitas, karena jauhnya peneliti dari fenomena topik yang diteliti mengurangi bias pengaruh peneliti pada fenomena tersebut (Emzir, 2012).

Wawancara mendalam, menurut Kriyantono (2010) adalah suatu cara mengumpulkan data atau informasi dengan cara langsung bertatap muka dengan informan agar mendapatkan data lengkap dan mendalam. Studi kepustakaan dan penelusuran data online. Menurut Nazir, studi kepustakaan dilakukan untuk mengetahui ilmu yang berhubungan dengan penelitian berkembang serta menghindari terjadiya publikasi yang tidak diinginkan (Nazir, 2011). Selain itu, penelusuran data online adalah tata cara melakukan penelusuran data melalui media online seperti internet atau media jaringan lainnya yang menyediakan fasilitas online sehingga memungkinkan peneliti dapat memanfaatkan data informasi online yang berupa data maupun informasi teori secepat atau semudah mungkin dan dapat dipertanggungjawabkan secara akademis (Bungin, 2011).

Dalam penelitian ini, penulis menggunakan teknik analisis data model Miles dan Huberman dengan cara mengumpulkan data dari berbagai sumber dengan melakukan wawancara mendalam. Studi kepustakaan dan penelusuran data online akan memberikan informasi sesuai dengan topik penelitian ini. Setelah semua data terkumpul, dilakukan reduksi data dengan memilih dan memusatkan perhatian pada data-data yang diperlukan agar lebih fokus. Kemudian, dilakukan penyajian data-data yang telah dipilih sesuai dengan keadaan di lapangan penelitian untuk diteliti lebih lanjut dan kemudian barulah dilakukan penarikan kesimpulan/verifikasi mengenai persepsi masyarakat Betawi mengenai fenomena ondel-ondel ngamen.

\section{Hasil Temuan dan Diskusi}

Ondel-ondel yang dahulu memiliki fungsi untuk menolak bala, seharusnya menjadi ikon budaya Betawi, dan juga digunakan sebagai bagian dari acara adat maupun acara rakyat Jakarta, tetapi kini Ondel-ondel digunakan sebagai alat untuk mengamen. Oleh karena itu, peneliti melakukan wawancara mendalam kepada masyarakat Betawi untuk mengetahui persepsi mereka terkait Ondel-ondel ngamen. Berikut adalah hasil yang didapatkan oleh penulis: 
Perlengkapan Pemain Ondel-Ondel Tidak Sesuai dengan Adat

Ondel-ondel dahulu dipercaya oleh masyarakat Betawi sebagai penolak bala, namun kini Ondel-ondel yang seharusnya merupakan budaya Betawi dan kesenian harus beralih menjadi alat bernilai ekonomis. Masyarakat Betawi mengetahui adanya penggunaan Ondel-ondel sebagai alat untuk mengamen berdasarkan banyaknya Ondel-ondel ngamen yang berada di pinggir jalan.

Dengan maraknya peristiwa tersebut menyebabkan masyarakat Betawi menaruh perhatian terkait penggunaan Ondel-ondel ngamen terlebih lagi Ondelondel tersebut tidak menggunakan menggunakan pakaian yang layak, jarang tampil berpasangan, dan tidak menggunakan peralatan yang lengkap seperti alat musik maupun pakaian adat untuk pemainnya. Pakaian yang kurang layak menimbulkan rasa prihatin bercampur kesal di kalangan masyarakat Betawi. Dengan pakaian dan juga peralatan yang kurang lengkap membuat para pemain Ondel-ondel terlihat hanya untuk memenuhi kepentingannya semata.

Sebagian besar masyarakat Betawi merasakan adanya penggunaan Ondel-ondel ke arah yang negatif. Ondel-ondel yang digunakan untuk sarana mengamen biasanya berpakaian lengkap seperti kembang kelapa, kebaya encim, baju sadaria atau ujung serong, selendang, dan sarung kotak-kotak (cukin), namun tidak dengan pemain dan alat musiknya.

Tabel 1. Perlengkapan Ondel-Ondel Ngamen

\begin{tabular}{|c|c|c|}
\hline No & Perlengkapan & Penjelasan \\
\hline 1. & Pakaian Pemain & $\begin{array}{l}\text { Pakaian pada pemain Ondel-ondel ngamen tidak sesuai } \\
\text { dengan tradisi yang ada. Pakaian pemain Ondel-ondel } \\
\text { ngamen biasanya hanya menggunakan baju kaus, celana } \\
\text { jeans, dan juga sandal jepit. Seharusnya para pemain } \\
\text { menggunakan pakaian adat Betawi. }\end{array}$ \\
\hline 2. & Pakaian Ondel-ondel & $\begin{array}{l}\text { Ondel-ondel yang digunakan untuk mengamen } \\
\text { menggunakan pakaian yang lengkap seperti kembang kelapa } \\
\text { dan baju adat Betawi yang diantaranya kebaya encim, baju } \\
\text { sadaria atau ujung serong, selendang, dan sarung kotak- } \\
\text { kotak (cukin). }\end{array}$ \\
\hline 3. & Alat Musik & $\begin{array}{l}\text { Alat musik yang digunakan untuk mengiring Ondel-ondel } \\
\text { ngamen jarang menggunakan alat musik daerah, kebanyakan } \\
\text { Ondel-ondel ngamen menggunakan speaker untuk mengiring } \\
\text { Ondel-ondel mereka. }\end{array}$ \\
\hline
\end{tabular}

Sumber: Diolah oleh penulis

Dengan maraknya peristiwa tersebut menyebabkan masyarakat Betawi menaruh perhatian terkait penggunaan Ondel-ondel ngamen terlebih lagi Ondelondel tersebut tidak menggunakan menggunakan pakaian yang layak, jarang tampil berpasangan, dan tidak menggunakan peralatan yang lengkap seperti alat musik maupun pakaian adat untuk pemainnya. Pakaian yang kurang layak menimbulkan rasa prihatin bercampur kesal dikalangan masyarakat Betawi. Dengan pakaian dan juga peralatan yang kurang lengkap membuat para pemain Ondel-ondel terlihat hanya untuk memenuhi kepentingannya semata.

Masyarakat Betawi kurang menyukai penggunaan Ondel-ondel untuk mengamen, karena mereka menganggap Ondel-ondel merupakan ikon Betawi sehingga tidak layak untuk digunakan sebagai alat mengamen. Walaupun mereka 
Iren Chienita, Eko Harry Susanto, Septia Winduwati: Persepsi Masyarakat Betawi Mengenai Fenomena Ondel-Ondel Ngamen

mengetahui bahwa pemain Ondel-ondel ngamen berusaha untuk memenuhi kebutuhan sehari-hari mereka.

Dengan demikian gagasan yang terbentuk oleh masyarakat Betawi terkait Ondel-ondel mengamen sesuai dengan teori aspek persepsi kognitif yang dikemukakan oleh Branca, et al (dalam Walgito, 2002:69) yang menyatakan bahwa aspek kognitif merupakan komponen pegetahuan atau informasi yang berisi tentang kepercayaan individu terhadap suatu sikap, hal ini dapat berupa apa yang telah individu lihat dan ketahui sehingga membentuk suatu ide atau gagasan tentang objek tersebut.

Ketidaksesuaian Ondel-Ondel Ngamen Di Masyarakat

Masyarakat Betawi merasa kesal dengan adanya Ondel-ondel ngamen karena menurut mereka, mencari keuntungan dengan menggunakan budaya yang dimana sudah ditetapkan sebagai ikon suatu daerah adalah hal yang tidak layak untuk dilakukan, namun mereka tidak dapat berbuat apa-apa.

Masyarakat Betawi juga merasa prihatin dengan munculnya Ondel-ondel ngamen dipinggir jalan, seharusnya kini Ondel-ondel memiliki fungsi sebagai bentuk dari kesenian budaya Betawi, namun karena kurangnya perhatian dan kebutuhan akan ekonomi mendesak menjadikan Ondel-ondel turun ke jalan untuk mengamen.

Tabel 2. Alasan Masyarakat Betawi

\begin{tabular}{cl}
\hline $\begin{array}{c}\text { Masyarakat } \\
\text { Betawi }\end{array}$ & \multicolumn{1}{c}{ Alasan } \\
\hline & $\begin{array}{l}\text { Masyarakat Betawi merasa kesal, karena bagi mereka Ondel-ondel } \\
\text { merupakan ikon Betawi sehingga tidak layak untuk dijadikan alat } \\
\text { mengamen. }\end{array}$ \\
Masyarakat Betawi prihatin dengan munculnya Ondel-ondel ngamen, \\
Tidak Mendukung \\
mereka menyarankan agar para pemain Ondel-ondel ngamen dapat \\
bergabung ke dalam sanggar-sanggar Betawi yang tersedia. \\
Masyarakat Betawi menganggap Ondel-ondel sebagai ikon dan juga \\
budaya Betawi sehingga tidak mendukung apabila Ondel-ondel dihadirkan \\
sebagai alat untuk mengamen.
\end{tabular}

Sumber: Diolah oleh penulis

Walaupun ada yang berpendapat bahwa mengamen dengan Ondel-ondel memiliki dampak positif, yaitu Ondel-ondel dapat dikenal oleh masyarakat luas, namun di sisi lain Ondel-ondel yang merupakan ikon Betawi apabila dijadikan alat untuk mengamen dapat merusak Ondel-ondel sebagai ikon Betawi itu sendiri.

Ada juga yang berpendapat bahwa ngamen merupakan pekerjaan halal namun bagi masyarakat Betawi mengamen dengan menggunakan Ondel-ondel adalah tindakan yang salah.

Beberapa perasaan individu di atas sesuai dengan teori aspek afektif (dalam Walgito, 2002) yang menyatakan bahwa afektif merupakan komponen perasaan yang menyangkut kesan atau perasaan individu dalam menafsirkan stimulus. Ini merupakan perasaan yang menyangkut aspek emosional subjektif dari individu terhadap objek persepsi, berisi perasaan memihak atau tidak memihak, mendukung atau tidak mendukung terhadap objek yang dipersepsi. 
Tindakan Masyarakat Betawi Terkait Ondel-Ondel Ngamen

Kekesalan dan keprihatinan masyarakat Betawi membuat mereka cenderung enggan memberikan uang kepada Ondel-ondel ngamen. Meskipun mengamen dengan Ondel-ondel membuat masyarakat Betawi kesal tetapi ada beberapa masyarakat yang memberikan sebagian uang mereka sebagai rasa dari kemanusiaan, namun tetap tidak mendukung penggunaan Ondel-ondel untuk mengamen.

Tabel 3. Tindakan Masyarakat Betawi

\begin{tabular}{|c|c|}
\hline Tindakan & Penjelasan \\
\hline \multirow{3}{*}{ Memberi } & $\begin{array}{l}\text { Iba dengan pemain Ondel-ondel ngamen yang berusaha } \\
\text { memenuhi kebutuhan sehari-hari mereka. }\end{array}$ \\
\hline & $\begin{array}{l}\text { Rasa kemanusiaan yang timbul untuk para pemain Ondel- } \\
\text { ondel ngamen. }\end{array}$ \\
\hline & $\begin{array}{l}\text { Ngamen menggunakan budaya merupakan tindakan yang } \\
\text { salah. }\end{array}$ \\
\hline \multirow[t]{2}{*}{ Tidak Memberi } & $\begin{array}{l}\text { Ondel-ondel ngamen dinilai menjelek-jelekan budaya Betawi } \\
\text { dan menyimpang dari fungsinya sebagai ikon dan budaya } \\
\text { Betawi. }\end{array}$ \\
\hline & $\begin{array}{l}\text { Tidak menyukai penggunaan Ondel-ondel sebagai alat untuk } \\
\text { mengamen. }\end{array}$ \\
\hline
\end{tabular}

Sumber: Diolah oleh penulis

Di samping itu, ada juga beberapa masyarakat yang tidak memberikan uang kepada Ondel-ondel ngamen karena menurut mereka Ondel-ondel ngamen merupakan perbuatan yang menyimpang terlebih lagi pemain Ondel-ondel ngamen yang tidak menggunakan pakaian rapi sehingga membuat mereka tidak memberikan uangnya.

Masyarakat Betawi berharap Ondel-ondel yang digunakan untuk mengamen dapat dirangkul dengan baik oleh sanggar-sanggar yang ada maupun membentuk sanggar sehingga tidak disalah gunakan. Selain itu berbagai cara juga dilakukan oleh Unit Pengelola Kawasan Perkampungan Budaya Betawi (UPKPBB) untuk melestarikan Ondel-ondel seperti menginventarisir sanggar-sanggar mengenai kegiatan Ondel-ondel seperti pagelaran kesenian regular di mana Ondel-ondel selalu dilibatkan ke dalam aktivitas tersebut, kemudian ada juga pengajuan anggaran untuk pembuatan Ondel-ondel setiap tahunnya.

Dengan demikian dapat dikatakan bahwa tindakan masyarakat Betawi terkait Ondel-ondel ngamen sesuai dengan teori aspek konatif (dalam Walgito 2002) yang menyatakan bahwa komponen tindakan meliputi perilaku yang tidak hanya diliihat secara langsung tetapi juga meliputi bentuk perilaku yang berupa pernyataan atau perkataan yang diucapkan seseorang dan berisi kecenderugan untuk bertindak atau bereaksi terhadap sesuatu objek yang dipersepsi. 
Iren Chienita, Eko Harry Susanto, Septia Winduwati: Persepsi Masyarakat Betawi Mengenai Fenomena Ondel-Ondel Ngamen

\section{Simpulan}

Pertama perlengkapan yang digunakan oleh para pemain Ondel-ondel ngamen tidak sesuai dengan adat yang berlaku, dimana seharusnya para pemain Ondel-ondel menggunakan pakaian adat Betawi dan alat musik tradisional. Kedua, masyarakat Betawi tidak mendukung penggunaan Ondel-ondel sebagai alat mengamen. Menurut masyarakat Betawi, menggunakan Ondel-ondel untuk mengamen adalah tindakan yang salah karena Ondel-ondel merupakan bagian dari budaya, ikon dan kesenian Betawi. Dimana seharusnya Ondel-ondel tidak disalahgunakan, melainkan dilestarikan sebagai budaya khas Betawi. Ketiga, mayoritas masyarakat Betawi cenderung tidak memberikan uang kepada Ondel-ondel ngamen karena tidak setuju dengan keberadaan Ondel-ondel ngamen serta para pemainnya tidak menggunakan pakaian yang layak. Namun demikian, ada sebagian masyarakat Betawi yang memberikan uang karena rasa kemanusiaan.

\section{Ucapan Terima Kasih}

Terima kasih kepada bapak H. Buhori, SH., MH, bapak Sarmili, bapak Misan, bapak Saifudin, bapak Mamat, bapak Aria, bang Uut, kak Febri, dan kak Shanti sebagai narasumber yang telah menyediakan waktu dan memberi informasi dalam penelitian ini. Peneliti juga mengucapkan terima kasih kepada para responden yang telah meluangkan waktunya untuk mengisi kuesioner yang disebarkan di Setu Babakan. Terima kasih kepada berbagai pihak dalam penyelesaian skripsi ini.

\section{Daftar Pustaka}

Badan Pusat Statistik (BPS). (2017, November 17). Angka Pengangguran Jakarta di Atas TPT Nasional. Retrieved Agustus 30, 2018, from Katadata: https://databoks.katadata.co.id/datapublish/2017/11/17/angka-pengangguranjakarta-di-atas-tpt-nasional

Bajari, Atwar. (2015). Metode Penelitian Komunikasi Prosedur, Tren, dan Etika. Bandung: Simbiosa Rekatama Media

Farisco, L. N. B. (2018, Maret 11). Fenomena Ondel-Ondel Jadi Pengamen Jalanan, Pemerintah Diminta Beri Pembinaan. Retrieved Agustus 27, 2018, from Jakarta Tourism, Ondel-Ondel. (2015). Retrieved Agustus 29, 2018, from Jakarta Tourism: http://jakarta-tourism.go.id/2015/node/501?language=id

Kriyantono, Rachmat. (2010). Teknik Praktis Riset Komunikasi. Jakarta: Kencana

Liputan6.com: https://www.liputan6.com/news/read/3361235/fenomena-ondelondel-jadi-pengamen-jalanan-pemerintah-diminta-beri-pembinaan

Moleong, Lexy J. (2008). Metodologi Penelitian Kualitatif. Bandung: PT Remaja Rosdakarya

Nasiri, M. (2016, Juni 22). Mengenal Makna Simbolik Ondel-Ondel. Retrieved Agustus 30, 2018, from CNN Indonesia: https://www.cnnindonesia.com/hiburan/20160622182515-241140178/mengenal-makna-simbolik-ondel-ondel

Nazir. (2011). Metode Penelitian. Bogor: Penerbit Ghalia Indonesia

Paramita, S. (2018). Pergeseran Makna Budaya Ondel-Ondel Pada Masyarakat Betawi Modern. Jurnal Bakti Masyarakat Indonesia, 1(1), 133-138

Walgito, Bimo. (2002). Pengantar Psikologi Umum. Yogyakarta: Andi Offset 